\title{
GEOPROCESSAMENTO APLICADO A ANÁLISE DA COBERTURA E USO DA TERRA NA ÁREA DE PROTEÇÃO AMBIENTAL DOS MANANCIAIS DO CÓRREGO LAJEADO, CAMPO GRANDE - MS
}

\author{
Bruna da Silva Andrade ${ }^{1}$ \\ Marta Regina da Silva Melo ${ }^{2}$ \\ Mauro Henrique Soares da Silva 3
}

\section{Resumo}

O monitoramento ambiental de Unidades de Conservação é fundamental para assegurar a manutenção da biodiversidade e efetiva proteção dessas áreas naturais. Desse modo, as técnicas de sensoriamento remoto e geoprocessamento são importantes ferramentas que permitem compreender as mudanças na cobertura do solo, auxiliando no diagnóstico ambiental e ordenamento territorial. Diante disso, objetivou-se avaliar a evolução da cobertura vegetal e uso da terra na Área de Proteção Ambiental dos Mananciais do Córrego Lajeado, entre os anos de 1995 e 2015, em Campo Grande, Mato Grosso do Sul. Verificou-se redução da vegetação em $3,95 \%$ e aumento de $11,26 \%$ de áreas urbanas na APA do Lajeado. Foram identificadas áreas com disposição indevida de resíduos sólidos e manejo inadequado do solo, os quais exercem pressões negativas sobre o ambiente.

Palavras-chave: Sistema de Informação Geográfica (SIG). Classificação Supervisionada. Análise da Paisagem. Unidades de Conservação.

\section{GEOPROCESSING APPLIED TO ANALYSIS OF THE SOIL USE IN THE ENVIRONMENTAL PROTECTION AREA OF MANANCIAIS DO CÓRREGO LAJEADO, CAMPO GRANDE - MS}

\begin{abstract}
The environmental monitoring of Conservation Units is fundamental to ensure the maintenance of biodiversity and effective protection of these natural areas. Thus, remote sensing and geoprocessing techniques are important tools for understanding changes in soil cover, assisting in environmental diagnosis and territorial planning. Therefore the objective of this study was to evaluate the evolution of vegetation cover and land use in Environmental Protection Area of Mananciais do Córrego Lajeado, between 1995 and 2015, in Campo Grande, Mato Grosso do Sul. During this period, vegetation was reduced by $3.95 \%$ and urban areas increased by $11.26 \%$ in the APA do Lajeado. Areas with undue disposition of solid wastes and inadequate soil management were identified, which exert negative pressures on the environment.

\footnotetext{
${ }^{1}$ Mestre em Meio Ambiente e Desenvolvimento Regional pela Universidade Anhanguera Uniderp, Campo Grande-MS. E- mail: andradebrunad@gmail.com.

${ }^{2}$ Doutorandaem Meio Ambiente e Desenvolvimento Regional pela Universidade para o Desenvolvimentodo Estadoe da Região do Pantanal - Uniderp (Campo Grande - MS). Mestre em Meio Ambiente e Desenvolvimento Regional pela Universidade para o Desenvolvimento do Estado e da Região do Pantanal - Uniderp (Campo Grande - MS).E-mail: martamelors@gmail.com

${ }^{3}$ Doutor pelo Programa de Pós-graduação em Geografia da UNESP, Campus de Presidente Prudente. Mestre em Geografia pela Universidade Federal de Mato Grosso do Sul.E-mail:mauro.soares@ufms.br
} 
Keywords: Geographic Information System (GIS). Supervised Classification. Landscape Analysis. Conservation Units.

\section{GEOPROCESAMIENTO APLICADO AL ANALISIS DEL USO Y OCUPACIÓN DEL SUELO EN EL ÁREA DE PROTECCIÓN AMBIENTAL DE LOS MANANCIAIS DEL CÓRREGO LAJEADO, CAMPO GRANDE - MS}

\section{Resumen}

El monitoreo ambiental de Unidades de Conservación es fundamental para asegurar el mantenimiento de la biodiversidad y efectiva protección de esas áreas naturales. De este modo, las técnicas de sensorización remota y geoprocesamiento son importantes herramientas que permiten comprender los cambios en la cobertura del suelo, auxiliando en el diagnóstico ambiental y ordenamiento territorial. El objetivo del estudio fue evaluar la evolución de la cobertura vegetal y el uso del suelo en el Área de Protección Ambiental de los Mananciais del Córrego Lajeado, entre los años 1995 y 2015, en Campo Grande, Mato Grosso do Sul. Se verificó reducción de la vegetación en el 3,95\% y aumento del 11,26\% de áreas urbanas en la APA del Lajeado. Se identificaron áreas con disposición indebida de residuos sólidos y manejo inadecuado del suelo, los cuales ejercen presiones negativas sobre el ambiente.

Palabras-clave: Sistema de Información Geográfica (SIG). Clasificación Supervisada. Análisis del paisaje. Unidades de Conservación.

\section{INTRODUÇÃO}

No Brasil, existem 2.309 Unidades de Conservação (UCs), que abrangem cerca de 2.546.797 km² do território nacional (MMA, 2019). Estas áreas detêm características ambientais relevantes, com função de assegurar a representatividade de amostras significativas e ecologicamente viáveis das diferentes populações, hábitats e ecossistemas do território nacional e das águas jurisdicionais, a fim de preservar o patrimônio natural existente (BRASIL, 2000).

O Sistema Nacional de Unidades de Conservação, Lei n 9.985/2000, classifica as UCs em duas categorias: Proteção Integral, cujo principal objetivo é a proteção da natureza; e de Uso Sustentável, a qual visa conciliar a conservação do ambiente e o uso sustentável dos recursos naturais.

O município de Campo Grande, Mato Grosso do Sul, possui 110 mil hectares de Unidades de Conservação, onde 99,68\% desse total é representado por UCs inseridas na categoria de Uso Sustentável, com destaque para as Áreas de Proteção Ambiental (APAs), 
SOCIEDADE E

TERRITÓRIO
ANDRADE, Bruna da Silva

MELO, Marta Regina da Silva

SILVA, Mauro Henrique Soares da

sendo estas: APA dos Mananciais do Córrego Guariroba, APA da Bacia do Córrego Ceroula e APA dos Mananciais do Córrego Lajeado (SANTOS e KRAWIEC, 2011).

Esta categoria de Unidade de Conservação é representada por áreas geralmente extensas, com certo grau de ocupação humana, constituída por terras públicas e/ou privadas. Dotada de atributos naturais importantes para a qualidade de vida e o bem-estar da população, as APAs têm por objetivo proteger a diversidade biológica, disciplinar o processo de ocupação e assegurar a sustentabilidade do uso dos recursos naturais (BRASIL, 2000).

Entretanto, devido à grande parte de sua extensão pertencer a propriedades privadas, as Áreas de Proteção Ambiental representam a categoria que mais sofrem impactos negativos (PHILLIPS, 2002; ESTEVES e SOUZA, 2014), oriundos do conflito de interesses no ordenamento do território e o alto grau de interferência antrópica, que podem resultar em danos ambientais, como a supressão de cobertura vegetal, disposição inadequada de resíduos sólidos e efluentes, incêndios florestais, caça predatória, entre outros.

Segundo Pádua (2012), uma vez que as APAs não demandam desapropriação de terras, não existe grande resistência ao seu estabelecimento, no entanto apenas a criação não garante sua efetiva proteção. Esteves e Souza (2014) relatam que a diferença entre uma APA e uma área não protegida é a elaboração do Plano de Manejo e gestão, logo, APAs que não possuem estes atributos, dificilmente cumprirão com a função de uma Unidade Conservação.

Santos e Krawiec (2011) apontam que, de maneira geral, as UCs do município de Campo Grande - MS apresentam carência de planejamento e técnicas de gestão ambiental, além de intensa descontinuidade administrativa, que comprometem seu gerenciamento e manutenção.

Neste sentido, pesquisas realizadas por Oliveira et al. (2009), Martins e Silva (2014), Pirajá e Silva (2014), Fonseca e Silva (2015) e Silva e Lopes (2018), relatam problemas ambientais nas APAs do município, como perda de solo, risco de erosão e redução da vegetação nativa.

Conforme citado anteriormente, esses danos ambientais podem ser intensificados diante do lento processo de elaboração do Plano de Manejo, como na APA dos Mananciais do Córrego Lajeado, instituída no ano de 2001, porém com Plano de Manejo inicialmente elaborado em 2009 (PMCG, 2012), o que configura oito anos de uso sem qualquer ordenamento apropriado do território.

Desse modo, o monitoramento e mapeamento do uso da terra constitui um importante meio de contribuir para o planejamento territorial e subsidiar estratégias de gestão ambiental e manejo, afim de assegurar a conservação da biodiversidade e qualidade de vida da população. 
Neste sentido, imagens de satélite vem sendo amplamente utilizadas, pois fornecem dados que auxiliam na compreensão espacial e monitoramento da superfície terrestre. A utilização de ferramentas de sensoriamento remoto e geoprocessamento são essenciais no processo de extração de informações contidas em imagens orbitais, permitindo a identificação de mudanças naturais e/ou antrópicas no território ao longo do tempo (FLORENZANO, 2011).

A classificação de imagens constitui uma das principais técnicas de extração de dados, e pode ser realizada tanto por interpretação visual como por classificação digital. Na interpretação visual, o foto-intérprete analisa a imagem, em geral uma composição colorida RGB, e identifica feições de interesse. Já o processo de classificação digital baseia-se no reconhecimento de padrões e objetos homogêneos, representados em um conjunto de pixels, ao qual se aplica o mapeamento de áreas pertencentes a uma classe espectral definida (JENSEN, 2005; NOVO, 2010).

Considerando o papel socioambiental das Unidades de Conservação, torna-se relevante conhecer o estado de conservação desses ambientes, através de ferramentas eficazes. Neste contexto, o objetivo deste trabalho foi avaliar a evolução da cobertura vegetal e uso da terra na Área de Proteção Ambiental dos Mananciais do Córrego Lajeado, entre os anos de 1995 e 2015, em Campo Grande - MS.

\section{MATERIAL E MÉTODOS}

\section{Área de estudo}

A Área de Proteção Ambiental dos Mananciais do Córrego Lajeado está localizada no município de Campo Grande, capital de Mato Grosso do Sul e abrange uma área de 52,37 km².

A APA situa-se a leste do perímetro urbano do município e é composta por área rural e urbana (Figura 1).

Localizado entre as Bacias Hidrográficas do Rio Paraguai e Paraná, o município apresenta variedade de recursos hídricos, como córregos e nascentes. Neste sentido, a criação da APA do Lajeado, por meio do Decreto Municipal $n^{\circ}$ 8.265/2001, esteve vinculada a necessidade de recuperação e conservação dos córregos Lajeadinho e Lajeado, cujo reservatório é responsável por aproximadamente $12 \%$ do abastecimento público de água de Campo Grande, configurando um importante sistema produtor de água bruta (PMCG, 2012). 


\section{SOCIEDADE E}

TERRITÓRIO
ANDRADE, Bruna da Silva

MELO, Marta Regina da Silva

SILVA, Mauro Henrique Soares da

Figura 1. Mapa de localização da Área de Proteção Ambiental dos Mananciais do Córrego Lajeado, Campo Grande - MS

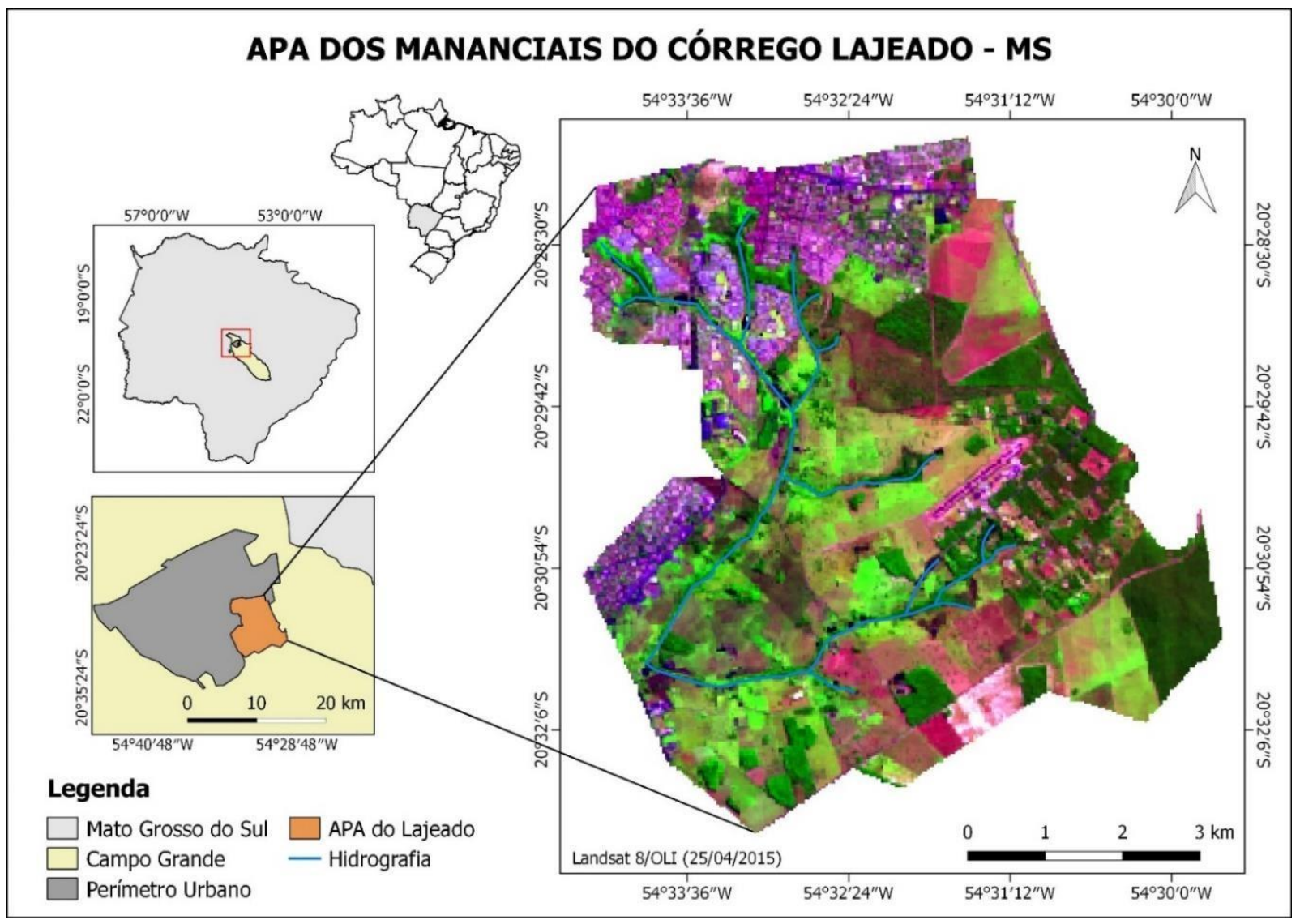

No entanto, de acordo com o Plano de Manejo, a ocupação nesta área de preservação ao longo dos anos, resultou em degradação na Bacia Hidrográfica do Córrego Lajeado, o que compromete a qualidade e a quantidade das águas destinadas ao abastecimento do município.

A região está inserida no bioma Cerrado, que constitui o segundo maior bioma brasileiro em extensão territorial, abrangendo uma área de $2.036 .448 \mathrm{~km}^{2}$ (IBGE, 2004). O Cerrado apresenta um gradiente de fitofisionomias, que engloba desde formações campestres até formas relativamente densas, como os cerradões (COUTINHO, 1978).

Considerado um hotspot ecológico, apresenta uma das maiores biodiversidades do mundo e alto grau de endemismo de espécies, contudo, constitui um dos biomas mais ameaçados do Brasil, devido principalmente à conversão de vegetação nativa em áreas de pastagem e agricultura, de modo que apenas $21 \%$ de sua extensão original permanece inalterada (CASTRO et al., 1999; HARRIS et al., 2005), destes, apenas 5,2\% está protegida por Unidades de Conservação (JEPSON, 2005). 
Na APA do Lajeado, o território é composto por pequenos fragmentos de mata nativa contornado por uma matriz antrópica de pastagem e plantação de culturas, caracterizada por um mosaico de fisionomias savânicas, campestres e florestais (PMCG, 2012).

\section{Procedimentos metodológicos}

Para alcance do objetivo proposto, o estudo foi pautado em duas etapas: o reconhecimento e caracterização da paisagem, que corresponde a etapa de campo; e a classificação supervisionada pixel a pixel de imagens orbitais, efetuada no Laboratório de Geoprocessamento da Universidade UNIDERP (Campo Grande - MS).

Foram obtidas imagens orbitais, gratuitamente, no banco de dados do Serviço Geológico dos EUA (USGS), sendo:

- Imagem do satélite LANDSAT 5, sensor TM (Thematic Mapper), órbita ponto 225/74, datada de 03/04/1995.

- Imagem do satélite LANDSAT 8, sensor OLI (Operational Land Imager), órbita ponto 225/74, datada de 26/04/2015.

A metodologia baseou-se em técnicas de tratamento de imagens, descritas por Novo (2010) e Florenzano (2011). O pré-processamento foi realizado em ambiente SIG (Sistema de Informações Geográficas), por meio de classificação supervisionada pixel a pixel, utilizando o complemento SCP (Semi-Automatic Classification Plugin).

A técnica permite realizar o mapeamento do uso da terra, dispondo de imagens de satélite e softwares livres, sendo possível obter parâmetros com altos níveis de precisão (VALE et al., 2018), o que demonstra a importância das geotecnologias para a produção de conhecimento de forma ampla e acessível.

Inicialmente, as imagens de satélite foram submetidas a correção atmosférica e conversão dos números digitais em reflectância de superfície, pelo método DOS (Dark Object Subtraction), visto que a calibração dos dados multitemporais é fundamental para padronização da escala radiométrica (SONG et al., 2001). Em seguida, as imagens foram recortadas a partir do arquivo shapefile da APA do Lajeado e associadas a composição RGB.

Com base na metodologia de Florenzano (2001), foi realizada a interpretação visual das imagens orbitais, onde foram avaliados os elementos: cor, textura, padrão, tamanho e forma, para identificação de diferentes feições e objetos na área. 
SOCIEDADE E

TERRITÓRIO
ANDRADE, Bruna da Silva

MELO, Marta Regina da Silva

SILVA, Mauro Henrique Soares da

\section{Verdade terrestre}

Realizou-se o levantamento de campo (verdade terrestre), que consiste em fase prévia essencial para a análise e processamento das imagens digitais. Nas visitas a campo, efetuou-se a caracterização das diferentes unidades da paisagem, registro de fotografias e coleta de coordenadas geográficas de 80 pontos de interesse, nos meses de outubro e dezembro de 2015.

\section{Chave de Interpretação}

A partir desses procedimentos, foi elaborada uma chave de interpretação com as principais unidades da paisagem que compõe o território da APA do Lajeado. Estas foram agrupadas de acordo com suas características e similaridades, observadas tanto em campo, como nas imagens digitais. Dessa forma, foram estabelecidas cinco classes temáticas principais: vegetação arbórea, pastagem, solo exposto, área urbana e corpo hídrico.

É importante ressaltar que cada pixel da imagem Landsat, possui resolução de 30 metros, portanto, dependendo da largura do corpo d'água, a mata ciliar o sobrepõe, sendo o recurso hídrico inferido indiretamente como vegetação (Florenzano, 2011).

\section{Classificação supervisionada}

Para a classificação supervisionada pixel a pixel, foram selecionadas amostras de treinamento com características espectrais associadas a classes temáticas representativas da área. Utilizou-se como referência os pontos coletados em campo (verdade terrestre), além de imagens do software Google Earth Pro e a plataforma MapBiomas. Posteriormente, aplicou-se o algoritmo de distância mínima, o qual compara a distância euclidiana entre o pixel e as médias de cada classe e o atribui a classe de menor distância.

\section{Validação estatística}

A validação estatística da classificação foi realizada através da matriz de confusão (CAMPBELL, 1987), a qual possibilita verificar a qualidade do processo de classificação, sendo expressa pela correlação entre os dados de referência e os dados classificados (FONSECA, 2000). Neste processo, utilizou-se como referência os pontos de verdade terrestre para a imagem de 2015, e as amostras de treinamento, para a imagem de 1995.

A partir da matriz de confusão foram aplicadas as medidas de precisão, sendo o Índice 
Kappa e Acurácia Global COHEN, 1960). A acurácia global é calculada pela divisão da soma dos elementos situados na diagonal da matriz de confusão xii, pelo número total de amostras coletadas $(\mathrm{N})$, conforme a Equação 1.

$$
G=\frac{\sum_{i=1}^{r} x_{i i}}{N}
$$

O cálculo do índice Kappa (Equação 2) inclui todos os elementos da matriz, sendo uma das medidas de precisão mais utilizadas para avaliação da qualidade do mapeamento (BRITES et al., 1996).

$$
K=\frac{N \sum_{i=1}^{r} x_{i i}-\sum_{i=1}^{r}\left(x_{i+} * x_{+i}\right)}{N^{2}-\sum_{i=1}^{r}\left(x_{i+} * x_{+i}\right)}
$$

Onde, $\mathrm{K}$ = valor do índice Kappa; $\mathrm{r}$ = número de linhas; $\mathrm{x}_{\mathrm{ii}}=$ número de observações na linha i e coluna $\mathrm{i} ; \sum_{i=1}^{r} x_{i i}=$ soma dos elementos da diagonal principal da matriz de confusão; $\mathrm{x}_{\mathrm{i}_{+}}=$total das observações das linhas $\mathrm{i} ; \mathrm{x}_{+\mathrm{i}}=$ total das observações das colunas $\mathrm{i} ; \mathrm{N}=$ número total de observações.

Os valores obtidos pelo índice Kappa, para cada imagem classificada, foram analisados de acordo com os intervalos e níveis de concordância estabelecidos por Landis e Koch (1977): péssimo $(0,00)$, ruim $(0,01$ a 0,20$)$, razoável $(0,21$ a 0,40$)$, bom $(0,41$ a 0,60$)$, muito bom $(0,61$ a 0,80$)$ e excelente $(0,81$ a 1,00$)$. 


\section{SOCIEDADE E}

TERRITÓRIO

ANDRADE, Bruna da Silva

MELO, Marta Regina da Silva

SILVA, Mauro Henrique Soares da

Tabela 1. Chave de interpretação da Área de Proteção Ambiental dos Mananciais do Córrego Lajeado, Campo Grande - MS

\begin{tabular}{|c|c|c|c|c|c|}
\hline $\begin{array}{l}\text { Unidades da } \\
\text { paisagem }\end{array}$ & $\begin{array}{c}\text { Imagem } \\
\text { Landsat RGB }\end{array}$ & $\begin{array}{l}\text { Feições da } \\
\text { imagem }\end{array}$ & $\begin{array}{c}\text { Imagem } \\
\text { Google Earth }\end{array}$ & $\begin{array}{l}\text { Coordenadas } \\
\text { geográficas }\end{array}$ & $\begin{array}{c}\text { Fotos de } \\
\text { campo }\end{array}$ \\
\hline Pastagem & & $\begin{array}{l}\text { Cor: marrom } \\
\text { Textura: lisa } \\
\text { Forma: regular }\end{array}$ & & $\begin{array}{c}20031^{\prime} 10.5^{\prime \prime} \mathrm{S} \\
54032^{\prime} 33.1^{\prime \prime} \mathrm{W}\end{array}$ & \\
\hline $\begin{array}{l}\text { Pastagem com } \\
\text { vegetação } \\
\text { arbórea e } \\
\text { rasteira } \\
\text { esparsa }\end{array}$ & & $\begin{array}{l}\text { Cor: verde oliva } \\
\text { Textura: lisa } \\
\text { Forma: irregular }\end{array}$ & & $\begin{array}{l}20030^{\prime} 44.8^{\prime \prime} \mathrm{S} \\
54032^{\prime} 48.7^{\prime \prime} \mathrm{W}\end{array}$ & \\
\hline $\begin{array}{l}\text { Pastagem } \\
\text { degradada } \\
\text { com solo } \\
\text { exposto }\end{array}$ & & $\begin{array}{c}\text { Cor: branco e } \\
\text { rosa } \\
\text { Textura: lisa } \\
\text { Forma: irregular }\end{array}$ & & $\begin{array}{l}20031^{\prime} 53.5^{\prime \prime} \mathrm{S} \\
54031^{\prime} 31.7^{\prime \prime} \mathrm{W}\end{array}$ & \\
\hline $\begin{array}{l}\text { Monocultura } \\
\text { (eucalipto) }\end{array}$ & & $\begin{array}{c}\text { Cor: verde } \\
\text { Textura: lisa } \\
\text { Forma: regular }\end{array}$ & & $\begin{array}{l}20029^{\prime} 52.5^{\prime \prime} \mathrm{S} \\
5432^{\prime} 58.0^{\prime \prime} \mathrm{W}\end{array}$ & \\
\hline $\begin{array}{l}\text { Vegetação } \\
\text { arbustiva }\end{array}$ & & $\begin{array}{c}\text { Cor: marrom, } \\
\text { verde a rosa } \\
\text { Textura: lisa } \\
\text { Forma: irregular }\end{array}$ & & $\begin{array}{l}20 \text { 을 } 17.9^{\prime \prime} \mathrm{S} \\
54032^{\prime} 14.4^{\prime \prime} \mathrm{W}\end{array}$ & \\
\hline $\begin{array}{c}\text { Vegetação } \\
\text { arbórea densa }\end{array}$ & & $\begin{array}{l}\text { Cor: verde } \\
\text { escuro } \\
\text { Textura: lisa } \\
\text { Forma: regular }\end{array}$ & & $\begin{array}{l}20031^{\prime} 52.4^{\prime \prime} \mathrm{S} \\
54031^{\prime} 46.7^{\prime \prime} \mathrm{W}\end{array}$ & \\
\hline Corpo hídrico & & $\begin{array}{c}\text { Cor: azul } \\
\text { Textura: lisa } \\
\text { Forma: regular }\end{array}$ & & $\begin{array}{c}20031^{\prime} 19.7^{\prime \prime} \mathrm{S} \\
54032^{\prime} 22.2^{\prime \prime} \mathrm{W}\end{array}$ & \\
\hline Área urbana & & $\begin{array}{l}\text { Cor: magenta } \\
\text { Textura: lisa } \\
\text { Forma: irregular }\end{array}$ & persis & $\begin{array}{l}20 \circ 30^{\prime} 34.3^{\prime \prime} \mathrm{S} \\
54033^{\prime} 47.7^{\prime \prime} \mathrm{W}\end{array}$ & \\
\hline Solo exposto & & $\begin{array}{c}\text { Cor: rosa } \\
\text { Textura: lisa } \\
\text { Forma: irregular }\end{array}$ & & $\begin{array}{l}20027^{\prime} 55.6^{\prime \prime} \mathrm{S} \\
54033^{\prime} 23.2^{\prime \prime} \mathrm{W}\end{array}$ & \\
\hline
\end{tabular}

Fonte: Elaboração dos autores. 


\section{RESULTADOS E DISCUSSÃO}

\section{Classes temáticas}

No processo de interpretação das imagens digitais, foram identificadas diferentes unidades da paisagem que caracterizam a APA do Lajeado, sendo: pastagem/campo, pastagem degradada com vegetação arbórea e rasteira esparsa, pastagem degradada com solo exposto, silvicultura (plantação de eucalipto), vegetação arbustiva, vegetação arbórea densa, corpo hídrico, área urbana e solo exposto (Tabela 1).

A classe vegetação corresponde as unidades de paisagem: vegetação arbórea densa e vegetação arbustiva. A classe silvicultura não foi considerada, visto que na interpretação de imagens digitais e históricas de 1995, não foi identificada presença significativa de monocultivo de eucalipto no interior da APA do Lajeado.

A classe pastagem constitui áreas de pasto com ou sem a presença de vegetação esparsa. Solo exposto corresponde a áreas de solo nu e pastagem degradada. Córregos, lagos e reservatórios de água estão representados na classe corpo hídrico. E a classe área urbana abrange edificações, construções e infraestrutura antrópica.

\section{Classificação e validação estatística}

$\mathrm{Na}$ validação estatística, os mapas temáticos foram qualificados como excelentes, de acordo com a classificação de Landis e Koch (1977) (Tabela 2).

Tabela 2. Validação estatística pela acurácia global e índice Kappa

\begin{tabular}{ccccl}
\hline Ano & Acurácia global & Qualidade & Índice Kappa & Qualidade \\
\hline 1995 & $95,83 \%$ & excelente & 0,91 & excelente \\
2015 & $97,64 \%$ & excelente & 0,93 & excelente \\
\hline
\end{tabular}

Como resultado da classificação, foi obtido o mapeamento da cobertura e uso da terra da APA do Lajeado, para os anos de 1995 e 2015, que permitiu compreender a distribuição espacial das referidas classes (Figura 2). 


\section{SOCIEDADE E}

TERRITÓRIO
ANDRADE, Bruna da Silva

MELO, Marta Regina da Silva

SILVA, Mauro Henrique Soares da

Figura 2. Mapa da cobertura vegetal da Área de Proteção Ambiental dos Mananciais do Córrego Lajeado, Campo Grande - MS, nos anos de 1995 e 2015

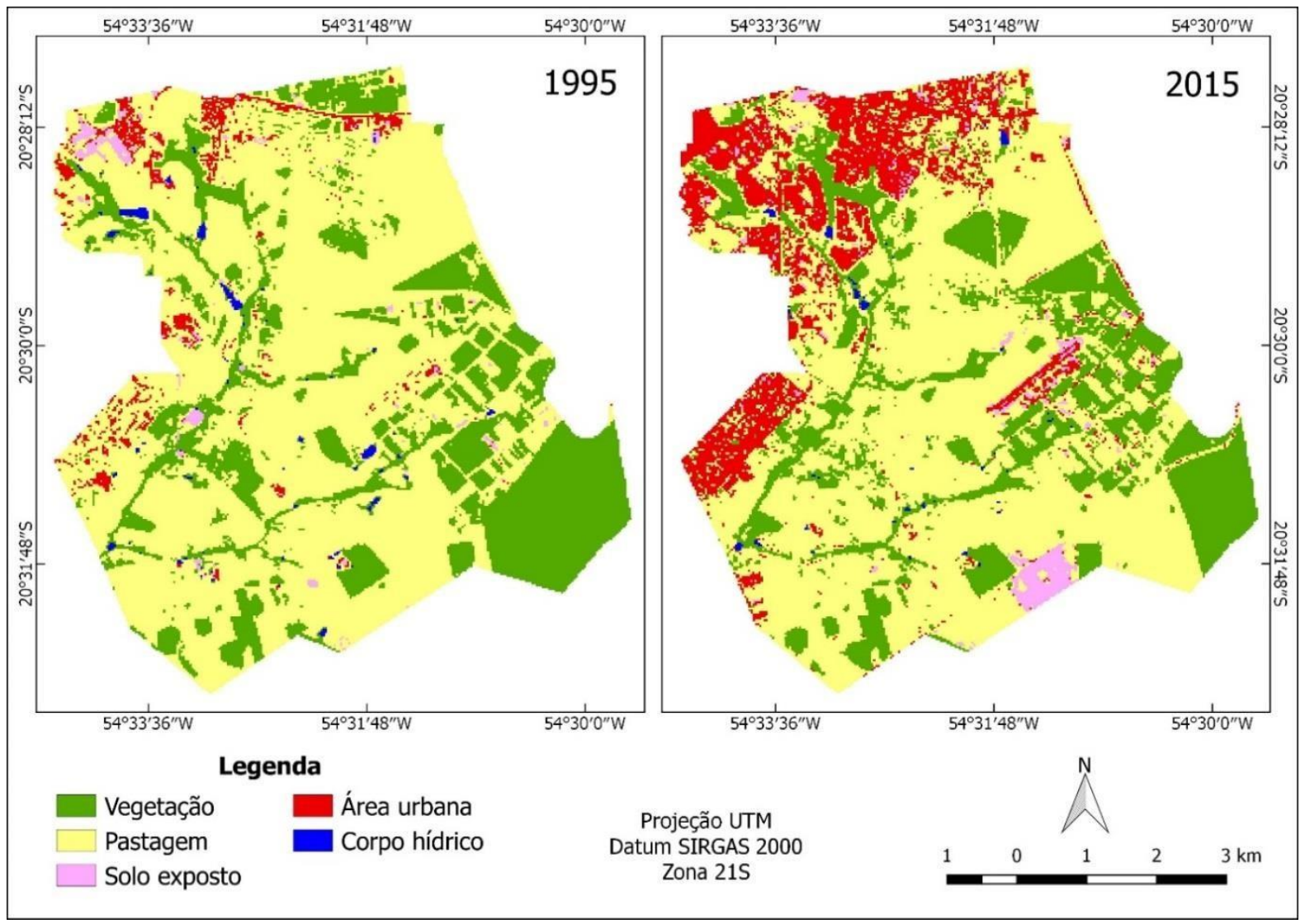

Os valores de área e a variação percentual de cada classe temática estão expressos na Tabela 3 e Figura 3, respectivamente.

Tabela 3. Extensão territorial de cada classe referente aos anos de 1995 e 2015, da Área de Proteção Ambiental dos Mananciais do Córrego Lajeado, Campo Grande - MS

\begin{tabular}{lccc}
\hline Classes & $\mathbf{1 9 9 5}\left(\mathbf{k m}^{\mathbf{2}}\right)$ & $\mathbf{2 0 1 5}\left(\mathbf{k m}^{\mathbf{2}}\right)$ & Variação $\left.\mathbf{( k m}^{\mathbf{2}}\right)$ \\
\hline Vegetação & 13,69 & 11,68 & $-2,01$ \\
Pastagem & 34,72 & 30,58 & $-4,14$ \\
Solo exposto & 0,6 & 1,16 & $+0,56$ \\
Área urbana & 1,54 & 7,27 & $+5,73$ \\
Corpo hídrico & 0,28 & 0,15 & $-0,13$ \\
\hline Total & 50,83 & 50,84 & \\
\hline
\end{tabular}

Os resultados obtidos demonstraram que a maior variação territorial se deu na classe área urbana, que passou de 1,54 km² no ano de 1995, para 7,27 km² (11,26\%) em 2015 (Tabela $3)$. 
A classe vegetação exibiu redução de $13,69 \mathrm{~km}^{2}$ para $11,68 \mathrm{~km}^{2}$, assim como a classe pastagem, que diminuiu de $34,72 \mathrm{~km}^{2}$ para $30,58 \mathrm{~km}^{2}$ entre 1995 e 2015. Já as classes solo exposto e corpo hídrico apresentaram discreta variação entre o período estudado (Tabela 3).

Figura 3. Variação percentual das classes temáticas entre 1995 e 2015 na Área de Proteção Ambiental dos Mananciais do Córrego Lajeado, Campo Grande - MS

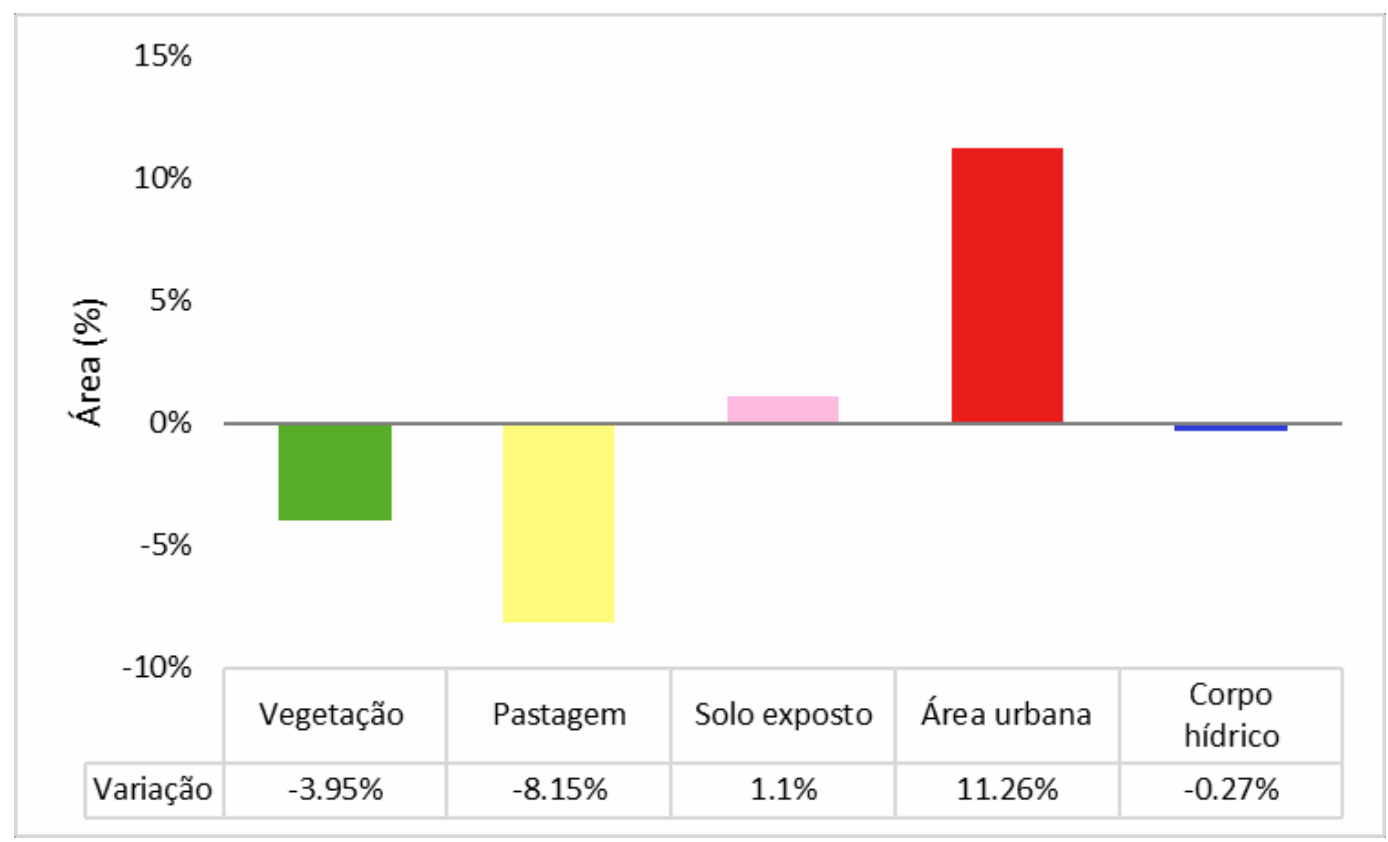

No que se refere a classe vegetação, apesar de sua discreta redução de 3,95\% em um período de 20 anos (Figura 3), é importante ressaltar que esta classe se restringe a 22,97\% da extensão total da APA do Lajeado, representando componente relevante da paisagem na Unidade de Conservação.

Parte da vegetação arbórea da APA refere-se a Áreas de Preservação Permanente, protegidas no âmbito da Lei $\mathrm{n}^{\circ} \mathbf{4 . 7 7 1 / 6 5}$, do Código Florestal brasileiro. No entanto, como relatado no Plano de Manejo, as matas ciliares localizadas dentro da APA, encontram-se abaixo da largura prevista por lei e em alguns trechos são ausentes, principalmente devido ao pisoteio pelo gado (PMCG, 2012), o que demonstra a necessidade de recuperação imediata dessas áreas florestais, de acordo com o sistema legislativo vigente.

Dessa forma, reduções na cobertura florestal da APA devem ser tratadas com atenção, uma vez que essas áreas são determinantes para a preservação de recursos hídricos importantes, que atuam no abastecimento de água no município de Campo Grande. Além disso, a redução da vegetação nativa resulta na perda de habitats para a fauna silvestre e compromete a manutenção da biodiversidade. 


\section{SOCIEDADE E}

TERRITÓRIO
ANDRADE, Bruna da Silva

MELO, Marta Regina da Silva

SILVA, Mauro Henrique Soares da

Em estudo realizado na Bacia Hidrográfica do Lajeadinho, Lima e Silva (2014) também apontam diminuição da vegetação, de $9,13 \mathrm{~km}^{2}$ para 7,27 km² entre 1994 e 2014, evidenciando o processo de remoção da cobertura vegetal arbórea na APA.

A redução de $8,15 \%$ da classe pastagem (Figura 3), a qual compõe cerca de $60 \%$ do território da APA, está relacionada principalmente ao acréscimo significativo da área urbana, além do aumento de pastagens degradadas. Visto que, diante da diminuição da capacidade de suporte da pastagem, as áreas de pasto degradado observadas associam-se a presença de clareiras e solo nu.

Foi verificado que em algumas áreas, o estado de conservação tanto do solo, quanto das pastagens encontra-se precário (Figura 4). Sendo este um fato crítico, visto que há um predomínio da atividade pecuária na porção rural da APA.

No Brasil, as principais causas de degradação de pastagens estão associadas ao excesso de lotação do gado, falta de reposição de nutrientes e ausência de práticas conservacionistas do solo. Este processo aumenta a exposição do solo e favorece a ação direta de intempéries como chuva e insolação, promove perda da camada superficial, redução da qualidade do solo e erosão (ZIMMER et al., 2012). E em regiões com solos arenosos e/ou com alto risco de erosão, o processo de degradação é mais acentuado, como é o caso da APA do Lajeado.

De acordo com Albernaz e Lima (2007) a degradação de pastagens tem consequências abrangentes, podendo ocasionar impactos a biodiversidade local e aos recursos hídricos, uma vez que o solo exposto mais suscetível a erosão, pode afetar mananciais de abastecimento d'água, interferindo na qualidade de vida de comunidades rurais e urbanas.

O Plano de Manejo confirma tais informações, expondo que a supressão da vegetação e degradação das pastagens e do solo, tem gerado expressivos impactos na bacia do córrego Lajeado, sobretudo no que se refere a processos erosivos e assoreamento dos corpos d'água naturais e da área de entorno no reservatório Lajeado (PMCG, 2012).

Em estudo na APA do Lajeado, Oliveira et al. (2009) apontam a região norte como a de maior fragilidade do solo, com valores permissíveis de perda de solo próximos a 0 . Nesta região verifica-se a predominância da classe dos Neossolos, caracterizado por valores baixos de tolerância a perda. Dessa forma, segundo os autores, na porção norte as nascentes dos córregos estão cercadas por áreas de elevado risco a erosão, sendo que a produção excessiva de sedimentos nesses locais pode comprometer a qualidade e quantidade de água disponível nos trechos seguintes da rede hidrográfica, diminuindo a vida útil do reservatório de abastecimento público. 
$\mathrm{Na}$ classe solo exposto, apesar do pequeno aumento de 1,1\%, foi possível observar mudanças na espacialização da classe entre 1995 e 2015 (Figura 3). Em 1995, as áreas de solo exposto estavam principalmente relacionadas à atual porção urbana, possivelmente devido à retirada de cobertura vegetal na época, para construção civil. Já em 2015, conforme os levantamentos de campo, o solo exposto está especialmente associado a áreas de pastagens com solo degradado (Figura 4).

\section{Figura 4. Pastagem degradada com presença de solo exposto na Área de Proteção Ambiental dos Mananciais do Córrego Lajeado, Campo Grande - MS}

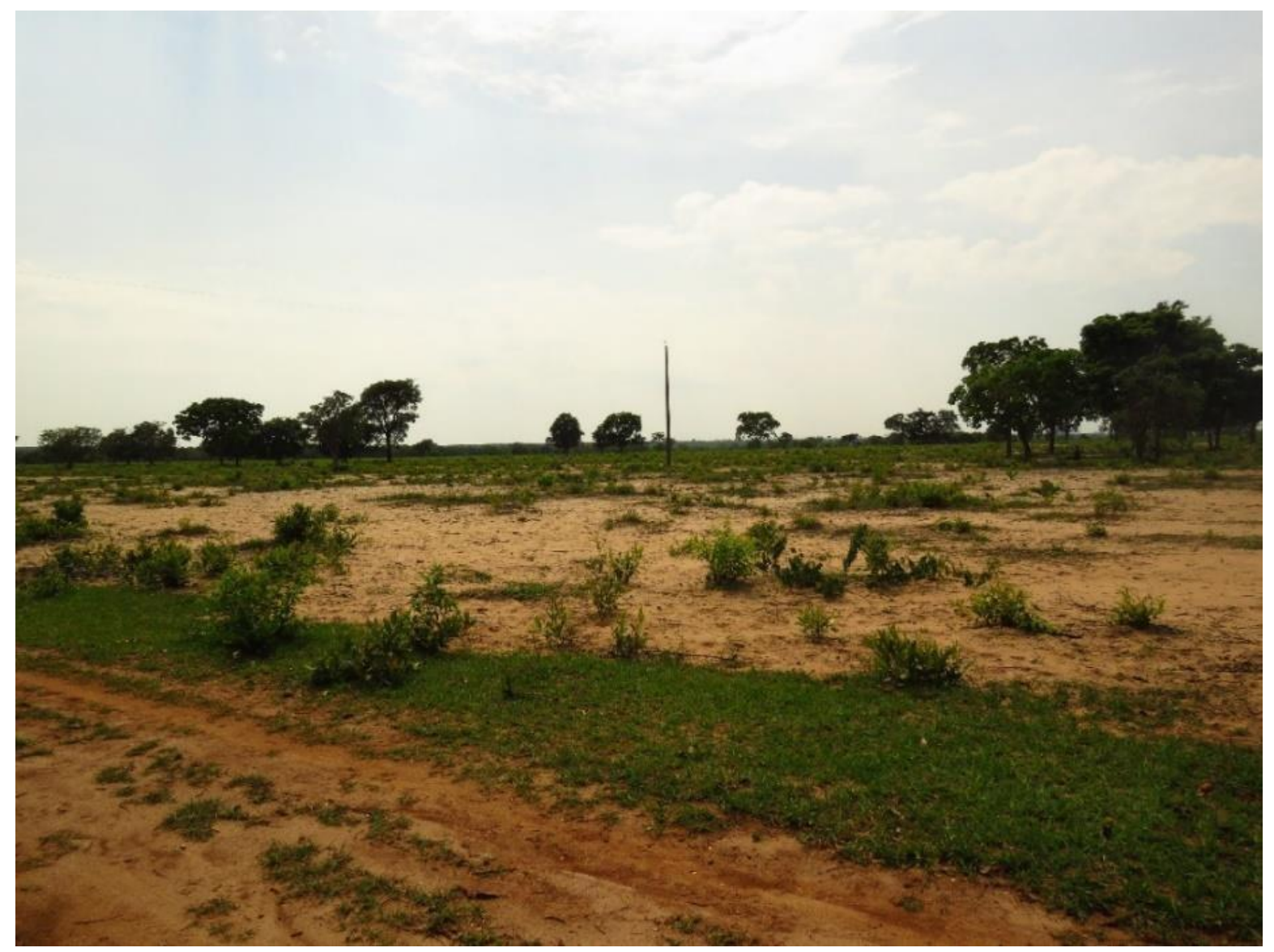

Fonte: Bruna da Silva Andrade.

Já a classe corpo hídrico exibiu redução de $0,28 \mathrm{~km}^{2}$ para $0,15 \mathrm{~km}^{2}(-0,27 \%)$, entre 1995 e 2015. Nas imagens digitais foram identificados um buritizal, lagos artificiais e reservatórios.

A extensão total dos córregos Lajeado e Lajeadinho não foi diagnosticada na classificação, podendo haver subestimação na estimativa desta classe.

Os elementos antrópicos da paisagem, representados pela classe área urbana, 


\section{SOCIEDADE E}

TERRITÓRIO
ANDRADE, Bruna da Silva

MELO, Marta Regina da Silva

SILVA, Mauro Henrique Soares da

compreendem 14,3\% da extensão territorial da APA e apresentaram aumento significativo de $11,26 \%$, sobretudo em áreas antes ocupadas por pastagens. A classe se concentra principalmente em sua porção noroeste (Figura 2). Deste modo, diferentemente das demais APAs de Campo Grande, a APA do Lajeado possui amplo percentual de paisagens urbanas, destacando-se a presença de residências, loteamentos, atividades comerciais e de serviços e indústrias de médio e grande porte (PMCG, 2012).

Em estudo na região, com recorte para a Bacia do Alto Lajeado, Fonseca e Silva (2015) encontraram resultados semelhantes, onde apontam acréscimo de 21,69\% da área urbana entre 1994 e 2014, e sugerem que a conversão tenha ocorrido em áreas de pastagem e vegetação nativa.

Verifica-se, portanto, que apesar de se tratar de uma Unidade de Conservação, o crescimento da área urbana no interior da APA, acompanhou o avanço da urbanização nas regiões periféricas do município. E essa expansão vem ocorrendo de maneira desarmônica, visto que foram identificados impactos negativos provindos da ocupação urbana na UC, principalmente quanto a instalação de empreendimentos e disposição inadequada de resíduos sólidos, que ocasionam problemas sanitários e ambientais (Figura 5).

Figura 5. Disposição inadequada de resíduos na Área de Proteção Ambiental dos Mananciais do Córrego Lajeado, Campo Grande - MS

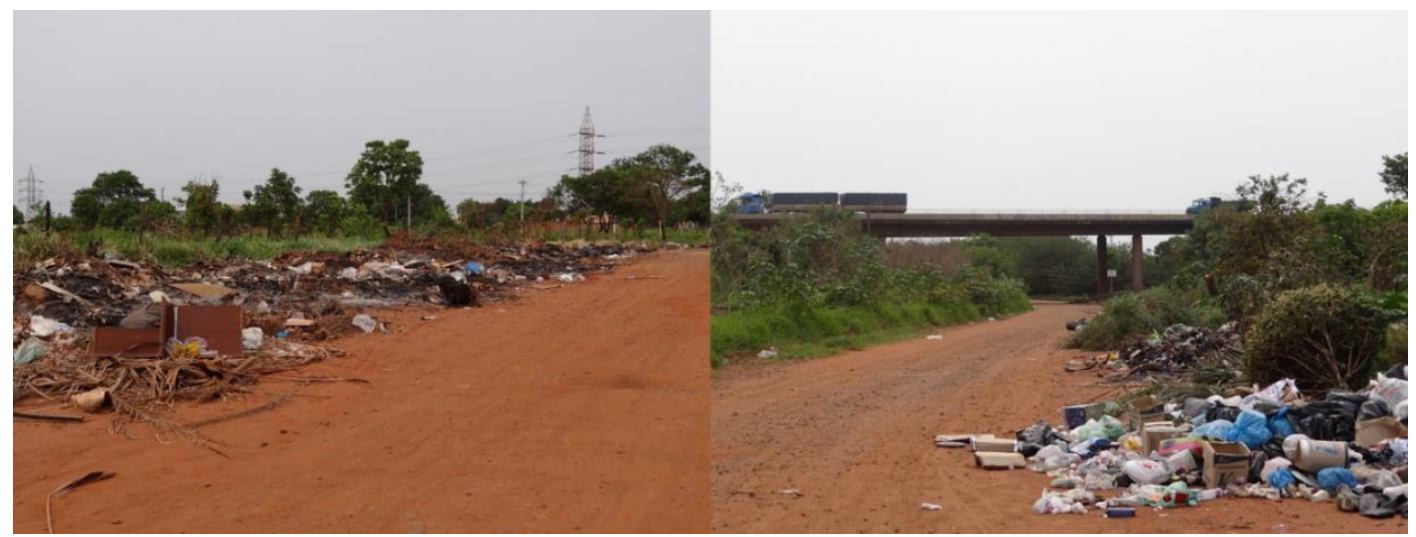

Fonte: Bruna da Silva Andrade. 
Destaca-se ainda, que este processo de expansão, sobretudo nas periferias, vem culminando em vazios urbanos dentro dos limites da UC (Figura 6). De acordo com Freitas e Negrão (2014) vazios urbanos caracterizam-se como áreas inutilizadas, subutilizadas ou em desuso, localizado em área urbanizada. Estes espaços presentes na malha urbana são consequências dos inúmeros processos históricos, políticos, econômicos e geográficos de determinado local. Ressalta-se que, ambos os autores citados sobre esse tema, consideram os vazios urbanos como um espaço concentrador de possíveis problemas urbanos, tanto ambientais quanto sociais.

\section{Figura 6. Vazios urbanos desprovidos de construção na Área de Proteção Ambiental dos Mananciais do Córrego Lajeado, Campo Grande - MS}

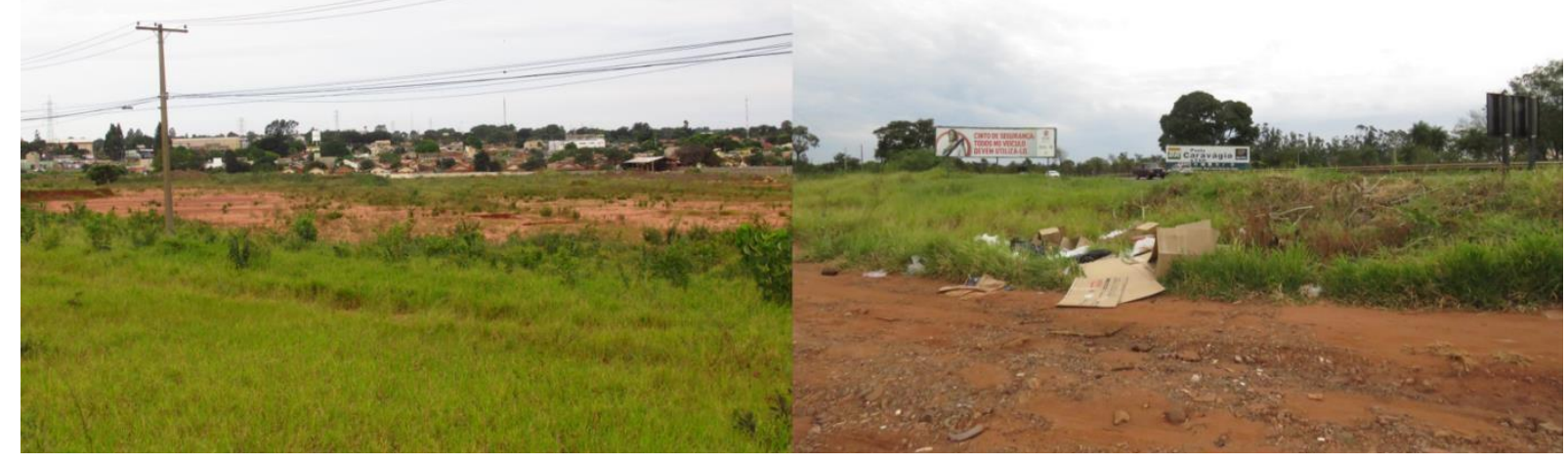

Fonte: Bruna da Silva Andrade.

Segundo a PMCG (2012), os vazios urbanos correspondem a 32,1\% da porção urbana da APA, sendo que destes, 148 hectares (cerca de 26\%) já possuem processos em tramitação ou em fase de consulta, para implantação de novos loteamentos residenciais. Vale destacar a complexidade urbana na APA, apresentada pela PMCG (2012), que relata além dos vazios urbanos, como componentes da paisagem desta UC, áreas industriais de médio e grande porte, residenciais multi e unifamiliares e áreas de comércio e serviços. (Figura 7)

Dessa forma, a APA do Lajeado reúne grupos sociais distintos, com diferentes atividades urbanas, o que gera a necessidade de sensibilizar e despertar a consciência crítica da comunidade local e entorno da UC, como ferramenta para conservação. Para Cerati e Lazarini (2009) estimular a participação da comunidade na proteção dos recursos naturais constitui ação 


\section{SOCIEDADE E}

relevante e fundamental para a efetiva proteção dessas áreas, sendo que essa consciência crítica pode ser despertada por meio da Educação Ambiental, que tem como desafio promover a mudança de valores, posturas e atitudes, integrando aspectos ecológicos, políticos, culturais e éticos.

Figura 7. Uso do solo, com destaque para a porção urbana da Área de Proteção Ambiental dos Mananciais do Córrego Lajeado, Campo Grande - MS (2012)

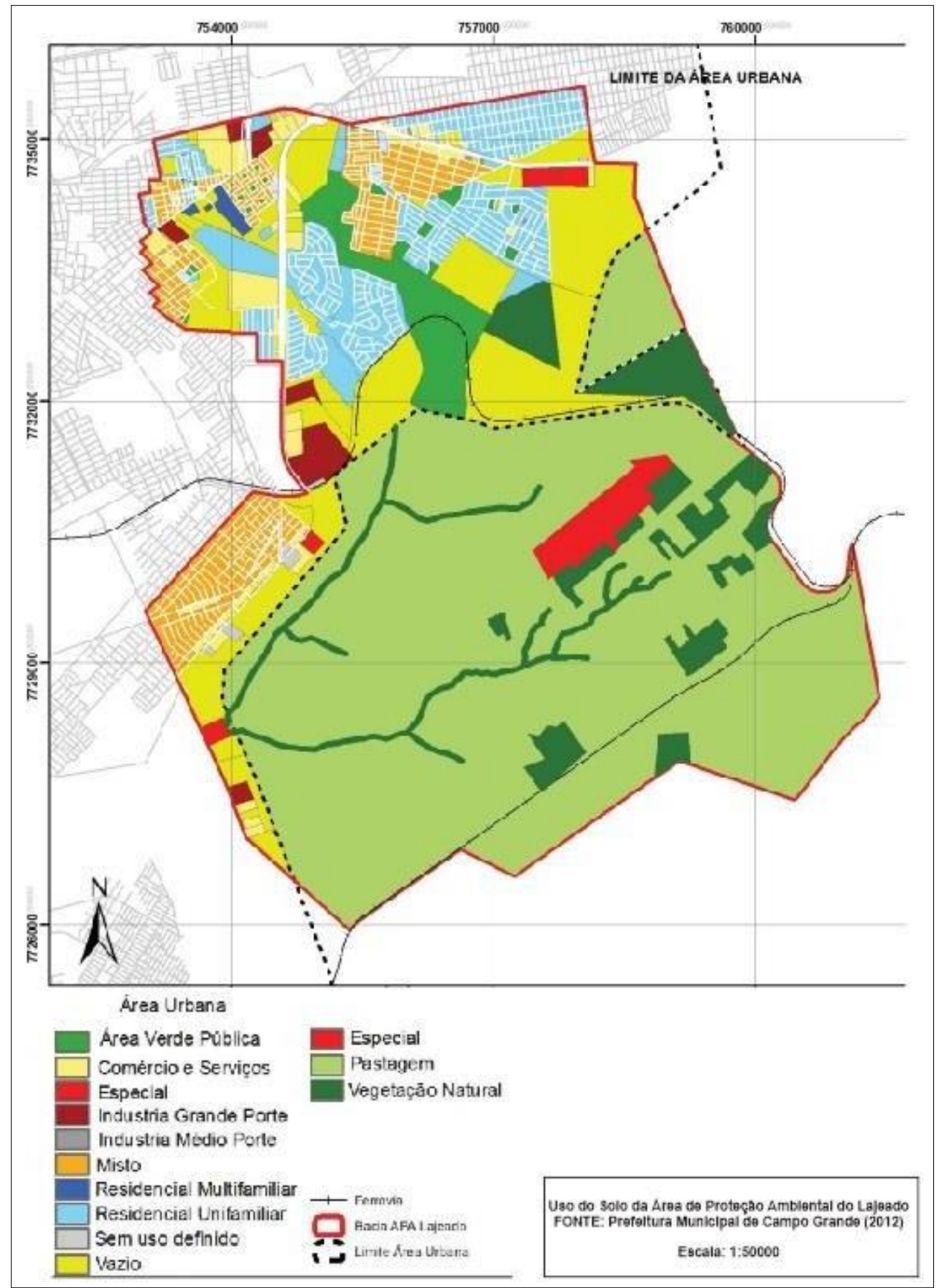

Fonte: PMCG (2012). 
Em suma, a configuração paisagística da área sugere problemas e riscos em detrimento do uso e ocupação da terra. De acordo com Costa et al. (2008), a ação antrópica (desmatamento, assoreamento e deposição de lixo) é um fator resultante de processos desordenados de urbanização que, no caso da área de estudo, tem avançado rapidamente, demonstrando divergências quanto ao real objetivo de uma Área de Proteção Ambiental: conciliar a conservação da natureza com o uso sustentável dos recursos naturais.

\section{CONCLUSÃO}

$\mathrm{O}$ uso de técnicas de sensoriamento remoto e geoprocessamento, aliadas ao diagnóstico em campo, mostrou-se uma ferramenta eficaz na análise e monitoramento das mudanças no uso da terra da Área de Proteção Ambiental do Lajeado.

De acordo com o estudo, o território da APA sofreu alterações na paisagem ao longo do período de 1995 e 2015, com redução da vegetação em 2,01 km² (3,95\%) e aumento da área urbana em 5,73 km² (11,26\%), seguido do solo exposto, com acréscimo de $0,56 \mathrm{~km}^{2}(1,1 \%)$. Foram verificadas pressões negativas sobre o ambiente associadas a ocupação antrópica na APA, como gestão inadequada dos resíduos sólidos e falta de manejo do solo e pastagens.

Os resultados evidenciaram ainda, como dinâmica de mudança na paisagem da APA do Lajeado, que o aumento da área urbana se deu, sobretudo, pela conversão de áreas de pastagens, e, muito sensivelmente substituindo áreas de vegetação arbórea. No entanto, as áreas de vegetação nativa existentes constituem predominantemente Áreas de Preservação Permanente, que necessitam de medidas de proteção, o que sugere que qualquer alteração nessas áreas, mesmo que em baixos percentuais, merecem atenção e cuidados.

No que tange aos objetivos e funções de uma Unidade de Conservação com viés de uso sustentável, como é o caso da APA do Lajeado, considera-se que há necessidade de ações em prol da manutenção dos recursos naturais, especialmente baseadas na sensibilização ambiental da população local, uma vez que configuram diversos usos do território, gerando riscos e impactos a UC, para que se reconheçam como responsáveis pela conservação da área.

Diante do cenário observado, sugere-se ainda medidas que garantam a conservação da biodiversidade, dos recursos hídricos e qualidade de vida da população, como programas de revegetação, práticas de conservação do solo nas propriedades rurais e obras civis e fiscalização por parte dos órgãos responsáveis. 
SOCIEDADE E

TERRITÓRIO
ANDRADE, Bruna da Silva

MELO, Marta Regina da Silva

SILVA, Mauro Henrique Soares da

Os resultados obtidos demonstram, sobretudo, a importância do mapeamento e monitoramento do uso da terra em áreas protegidas e a necessidade de um planejamento territorial amplo, que vise a gestão participativa e manejo sustentável da APA do Lajeado.

\section{REFERÊNCIAS}

ALBERNAZ, Walfrido Machado; LIMA, José Maria de. Caracterização da cobertura vegetal de pastagens em duas sub-bacias hidrográficas da região de Lavras, MG. Ciência e Agrotecnologia, v. 31, n. 2, p. 290-297, mar./abr. 2007.

BRASIL. Lei no 9.985, de 18 de julho de 2000. Institui o Sistema Nacional de Unidades de Conservação da Natureza e dá outras providências. Brasília, 2000. Disponível em:

http://www.planalto.gov.br/ccivil_03/leis/L9985.htm. Acesso em 20 abr. 2016.

BRITES, Ricardo Seixas; SOARES, Vicente Paulo; RIBEIRO, Carlos Antonio Alvares Soares. Verificação da exatidão global em classificações de uma imagem orbital mediante a utilização de três índices. Revista Árvore, v. 20, n. 3, p. 415-424, out. 1996.

CAMPBELL, James. Introduction to remote sensing. 1 ed. New York: The Guilford Press, 1987.

CASTRO, Antonio Alberto Jorge Farias; MARTINS, Fernando Roberto; TAMASHIRO, Jorge Yoshio; SHEPHERD, George John. How Rich is the Flora of Brazilian Cerrados? Annals of the Missouri Botanical Garden, v. 86, n. 1, p.192-224, 1999.

CERATI, Tania Maria; LAZARINI, Rosmari Aparecida de Morais. A Pesquisa-ação em educação ambiental: uma experiência no entorno de uma Unidade de Conservação urbana.

Ciência \& Educação, v. 15, n. 2, p. 383-92, 2009.

COHEN, Jacob. Coefficient of agreement for nominal scales. Educational and Psychological Measurement, v. 20, n. 1, p. 37-46, abr. 1960.

COSTA, Neylanda France Abreu; CASTRO, Antonio Carlos Leal de; COSTA, Nytia Nanda Silva. Efeitos da urbanização na Área de Proteção Ambiental do Itapiracó. Boletim do Laboratório de Hidrobiologia, v. 21, n. 1, p. 9-16, 2008.

COUTINHO, Leopoldo Magno. O conceito de cerrado. Revista Brasileira de Botânica, v. 1, n. 1, p. 17-23, 1978.

ESTEVES, Aline Oliveira; SOUZA, Marcelo Pereira. Avaliação Ambiental Estratégica e as Áreas de Proteção Ambiental. Engenharia Sanitária e Ambiental, v. 19, n. especial, p. 77- 86, 2014. 
FLORENZANO, Teresa Gallotti. Iniciação em sensoriamento remoto. 3 ed. São Paulo: Oficina de Textos, 2011.

FONSECA, Diego Rezende da; SILVA, Mauro Henrique Soares da Silva. Análise multitemporal do uso e ocupação do solo da Bacia Hidrográfica do Alto Lajeado. In: BENINI, Sandra Medina (Org.). Uso de Sistemas de Informação Geográfica na análise ambiental em Bacias Hidrográficas. 1 ed. Tupã: ANAP, 2015. p. 81-97.

FONSECA, Leila Maria Garcia. Processamento digital de imagens. São José dos Campos: Instituto Nacional de Pesquisas Espaciais (INPE), 2000.

FREITAS, Marina Roberta; NEGRÃO, Glauco Nonose. Vazios Urbanos: Estudo de caso no município de Guarapuava-PR. Geographia Opportuno Tempore, v. 1, n. especial, p. 480- 493, jul./dez. 2014.

HARRIS, Mônica; TOMAS, Walfrido Moraes; MOURÃO, Guilherme; SILVA, Carolina; GUIMARÃES, Erika; SONODA, Fátima; FACHIM, Eliani. Desafios para Proteger o pantanal brasileiro: Ameaças e iniciativas em conservação. Megadiversidade, v. 1, n. 1, p. 156-164, jul. 2005.

IBGE. Instituto Brasileiro de Geografia Física. Mapa de Biomas do Brasil, primeira aproximação. Rio de Janeiro: IBGE, 2004. Disponível em:

https://ww2.ibge.gov.br/home/presidencia/noticias/21052004biomashtml.shtm. Acesso em: 05 mai. 2019.

JENSEN, John. Introductory digital image processing: a remote sensing perspective. 3 ed. Upper Saddle River: Prentice-Hall, 2005.

JEPSON, Wendy. A disappearing biome? Reconsidering land-cover change in the Brazilian savanna. The Geographical Journal, v. 171, n. 2, p. 99-111, jun. 2005.

LANDIS, J. Richard.; KOCH, Gary. The measurement of observer agreement for categorical data. Biometrics, v. 33, n. 1, p. 159-174, mar. 1977.

LIMA, Felipe Leite; SILVA, Mauro Henrique Soares. Avaliação das Mudanças na Paisagem da Bacia Hidrográfica do Lajeadinho em Campo Grande-MS, por meio de análise multitemporal. Fórum Ambiental da Alta Paulista, v. 10, n. 2, p. 513-524, 2014

MARTINS, José Lucas Ferreira; SILVA, Mauro Henrique Soares. Aplicação do Índice de Vegetação por Diferença Normalizada (NDVI) para avaliação ambiental da bacia hidrográfica do Alto Guariroba, Campo Grande - MS. Fórum Ambiental da Alta Paulista, v. 10, n. 2, p. 499-512, 2014.

MMA. Ministério do Meio Ambiente. Cadastro Nacional de Unidades de Conservação CNUC, 2018. Disponível: http://www.mma.gov.br/areas-protegidas/cadastro-nacional-de-ucs. Acesso em: 02 jun. 2019. 
NOVO, Evlyn Marcia Leão de Moraes. Sensoriamento Remoto: princípios e aplicações. 4 ed. São Paulo: Blucher, 2010.

OLIVEIRA, Paulo Tarso Sanches; SOBRINHO, Teodoro Alves; RODRIGUES, Dulce. Mapeamento do risco a erosão na Área de Proteção Ambiental do Córrego Lajeado, MS. In: XIV Simpósio Brasileiro de Sensoriamento Remoto, 2009, Natal. Anais de resumo. Natal: INPE, 2009. p. 4133-4140.

PÁDUA, Maria Tereza Jorge. Unidades de Conservação no Brasil: Lutando por Parques de verdade. In: PALAZZO JUNIOR, José Truda; CARBOGIM, João Bosco Priamo.

Conservação da Natureza: E eu com isso?. 1 ed. Fortaleza: Fundação Brasil Cidadão, 2012.

PHILLIPS, Adrian. Management Guidelines for IUCN Category V Protected Areas: Protected Landscapes/Seascapes. Cambridge, U.K. e Gland Switzerland: IUCN, 2002.

PIRAJÁ, Renan Vilhena; SILVA, Mauro Henrique Soares da. Vulnerabilidade Natural da Área de Proteção Ambiental do Córrego Ceroula, Campo Grande, Mato Grosso do Sul. In: V Simpósio de Geotecnologias no Pantanal, 2014. Anais de resumo. Campo Grande: Embrapa Informática Agropecuária/INPE, 2014. p. 100-109.

PMCG. Prefeitura Municipal de Campo Grande. Plano de Manejo da Área de Proteção Ambiental dos Mananciais do Córrego Lajeado - APA do Lajeado. Campo Grande, 2012. Disponível em: http://www.campogrande.ms.gov.br/semadur/downloads/apa-lajeado-plano- demanejo-2009/. Acesso em: 20 abr. 2018.

SANTOS, Cristiano Figueiredo dos; KRAWIEC, Viviane Amendola da Motta. A Situação Ambiental e a Administração das Unidades de Conservação em Campo Grande - MS, na visão de seus Gestores. Revista Floresta e Ambiente, v. 18, n. 3, p. 334-342, jul./set. 2011.

SILVA, Mauro Henrique Soares da; LOPES, Michele Macedo. Uso do Solo e Aspectos da Paisagem na Bacia Hidrográfica do Angico, na Área de Proteção Ambiental do Ceroula Campo Grande, MS. Revista Formação, v. 25, n. 44. p. 261-277, jan./abr. 2018.

SONG, Conghe; WOODCOCK, Curtis; SETO, Karen; LENNEY, Mary Pax; MACOMBER, Scott. Classification and change detection using Landsat TM data: when and how to correct atmospheric effects?. Remote Sensing of Environment, v. 75, n. 2, p. 230-244, fev. 2011.

VALE, Jones Remo Barbosa; COSTA, Jamer Andrade da; SANTOS, Jefferson Ferreira dos; SILVA, Elton Luis Silva da; FAVACHO, Artur Trindade. Análise comparativa de métodos de classificação supervisionada aplicada ao mapeamento da cobertura do solo no município de Medicilândia, Pará. InterEspaço, v. 4, n. 13, p. 26-44, jan./abr. 2018.

ZIMMER, Ademir, Hugo; MACEDO, Manuel Claudio Motta; KICHEL, Armindo Neivo; ALMEIDA, Roberto Giolo de. Degradação, recuperação e renovação de pastagens. Brasília: Embrapa Gado de Corte, 2012. (Documentos, 1989). 